\title{
Bronchogenic Cyst in a 23-Month-Old Infant at the University Hospital of Brazzaville
}

\author{
Moyen Engoba ${ }^{1,2}{ }^{*}$, B. Diall'1, Ngamo L. Tchidjo', M. F. Mitsomoy ${ }^{1,3}$, \\ A. L. Batchi-Bouyou', G. M. Moyen'1 \\ ${ }^{1}$ Faculty of Health Sciences, University Marien Ngouabi, Brazzaville, Republic of the Congo \\ ${ }^{2}$ Pediatric Intensive Care Department, University Hospital of the Brazzaville, Brazzaville, Republic of the Congo \\ ${ }^{3}$ Multipurpose Surgery Service, Cardiothoracic Surgery Unit, University Hospital of Brazzaville, Brazzaville, Republic of the Congo \\ Email: *engoba_m@yahoo.fr
}

How to cite this paper: Engoba, M., Diall, B., Tchidjo, N.L., Mitsomoy, M.F., Batchi-Bouyou, A.L. and Moyen, G.M. (2021) Bronchogenic Cyst in a 23-Month-Old Infant at the University Hospital of Brazzaville. Open Journal of Pediatrics, 11, 770-776. https://doi.org/10.4236/ojped.2021.114071

Received: September 4, 2021

Accepted: December 12, 2021

Published: December 15, 2021

Copyright $\odot 2021$ by author(s) and Scientific Research Publishing Inc. This work is licensed under the Creative Commons Attribution International License (CC BY 4.0).

http://creativecommons.org/licenses/by/4.0/

\begin{abstract}
The bronchogenic cyst, a congenital pulmonary malformation of often late revelation is rare. Its clinical manifestation, depending on the size of the cyst and its location, is dominated by respiratory symptoms. We report a case of a bronchogenic cyst in a 23-month-old infant treated with salbutamol combined with corticosteroid therapy for a third episode of breathing difficulty and wheezing. A chest X-ray and CT scan guided the diagnosis. Histological confirmation was made on an operative specimen after removal of the cyst. The immediate and mid-term outcome was good.
\end{abstract}

\section{Keywords}

Bronchogenic Cyst, Respiratory Distress, Infant, Surgery, Brazzaville

\section{Introduction}

Infant wheezing respiratory disease is common in daily pediatric practice [1] [2]. The difficulty of its management depends on its etiological research. The most represented are viral bronchopneumopathies [1] [2] which can be a source of diagnostic wandering likely to jeopardize the vital prognosis. This is the case with congenital pulmonary malformations, including bronchogenic cysts, most of which are located in the mediastinum ( $85 \%$ of cases), are often diagnosed unexpectedly at late stages on patients presenting with difficulty breathing [3] [4]. But, its discovery in infants, although exceptional, is not uncommon [5] [6] [7] [8]. We report a case of a bronchogenic cyst in an infant treated for bronchiolitis at the University Hospital of Brazzaville. This case report underscores the need to mention, in addition to bronchopneumopathies, a congenital pulmonary 
malformation, in the case of persistent respiratory difficulty and progressive aggravation.

\section{Case Report}

Junior, 23-month-old infant, male is hospitalized for breathing difficulties in November 2019 in the Pediatric Intensive Care Department University Hospital of the Brazzaville. Four days before his admission, he presented with a dry cough and gradually worsening respiratory distress. Intravenous Betamethasone and Salbutamol have been administered in a doctor's office with no clinical improvement. This clinical picture motivated his admission to the University Hospital of Brazzaville.

Junior was born at term after an uneventful pregnancy and delivery. The pregnancy was monitored by a midwife. Three ultrasounds performed were all normal. He weighed 3200 grams for $51 \mathrm{~cm}$ in size.

His medical history reveals two previous hospitalizations for bronchiolitis at six and seven months of age successfully treated with betamethasone and beta-2-mimetics. He is the third of his siblings; the other two were in apparent good health. No history of asthma or other atopy has been found. His father, jeweler, mother, housewife, non-consanguineous are Congolese, non-smokers and in apparent good health.

On admission, there was polypnea, the respiratory rate was 70 cycles per minute, the partial oxygen saturation in ambient air at $82 \%$, the temperature at $37^{\circ} \mathrm{C}$. He weighed $10 \mathrm{~kg}$ for $82 \mathrm{~cm}$ of height, $49 \mathrm{~cm}$ of head circumference, weight for age and height for age ratio were below $-1 \mathrm{Z}$ score, head circumference for age ratio was above the median, body mass index at $14.87 \mathrm{~kg} / \mathrm{m}^{2}$ is the median. The state of hydration was good.

There was evidence of respiratory struggle with chest indrawing, nasal flaring and grunting, but there was no cyanosis. On auscultation, there was an increase in vesicular murmur and wheezing rales in both lung fields. The clinical examination of the other organs showed no abnormalities.

A frontal chest X-ray showed a hydric tone opacity widening the upper mediastinum with external contours convex inwardly, and with internal edge embedded in the middle mediastinum, in connection with a mediastinal syndrome (Figure 1). The complete blood count, blood ionogram and serum creatinine showed no abnormalities. Blood gas was not realized. The hypothesis of an exacerbation of asthma was retained, and mask oxygen therapy associated with nebulized salbutamol, betamethasone, as well as hydration adapted to needs, were administered.

The persistence of breathing difficulty with periods of worsening led to a second chest X-ray after five days of treatment, which showed images similar to the first X-ray. A thoracic computed tomography (CT) performed on the eighth day showed an axial and sagittal CT scan of the thorax in the mediastinal window noted a voluminous retro-tracheal mediastinal mass with a fluid density of 
$35 \mathrm{~mm}$ located above the carina, responsible for a slight effect of mass on the trachea. The axial CT view through a parenchymal window showed alveolar filling of the right middle lobe (Figure 2).

A right vertical midaxillary thoracotomy performed showed a normal right lung and a bronchogenic cyst about $6 \mathrm{~cm}$ long and $4 \mathrm{~cm}$ in diameter, bounded below by the arch of the azygos, medially by the phrenic nerve, the vein superior cave, the brachiocephalic arterial trunk, lower by the trachea, above by the dome of the rib cage and the clavicular vessels. The cyst was in contact with the space of the Baréty compartment medially and anteriorly and with the chest wall and dorsal spine posteriorly. There was no mediastinal lymphadenopathy or other organ abnormalities. Complete extraction of the cyst was then performed. Macroscopically, it was a nodular, whitish, rounded, encapsulated formation measuring

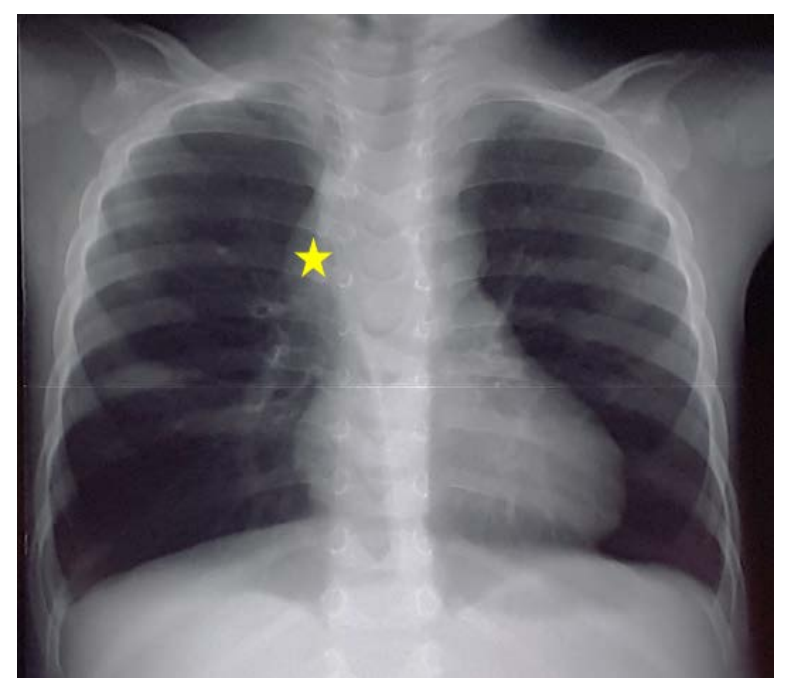

Figure 1. Frontal chest X-ray. Hydric tone opacity widening the upper mediastinum with external contours convex inwardly (yellow star), and with internal edge embedded in the middle mediastinum, in connection with a mediastinal syndrome.
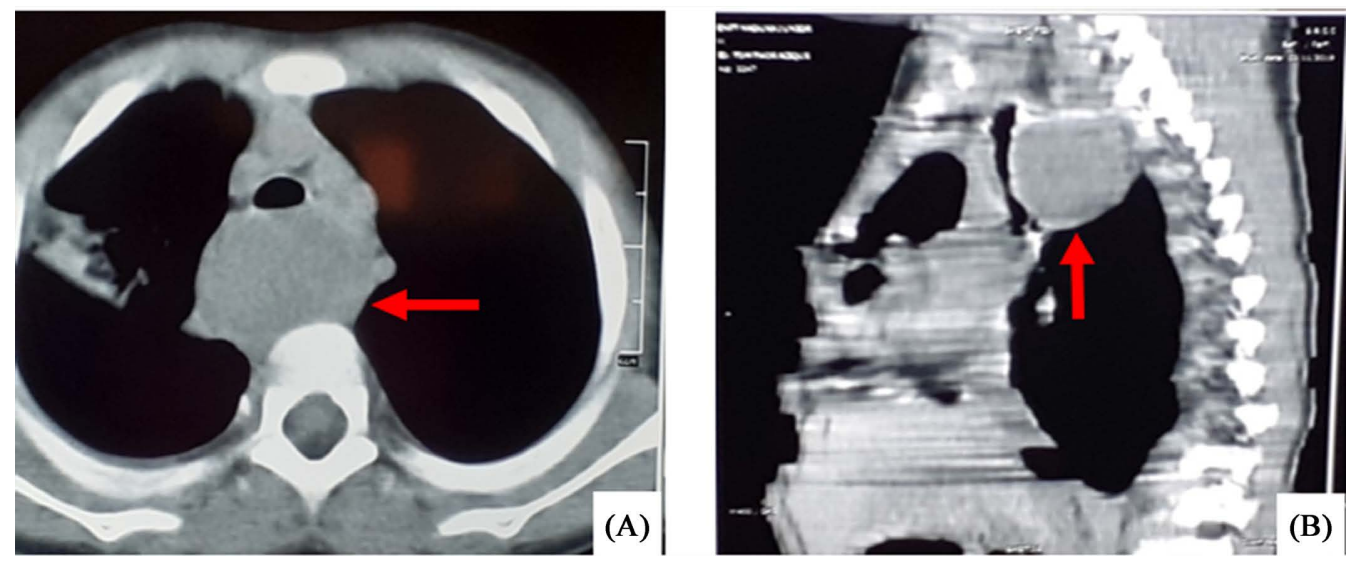

Figure 2. Axial (A) and sagittal (B) CT scan of the thorax in the mediastinal window showing a bulky retrotracheal mediastinal mass (red arrows), of fluid density, of $35 \mathrm{~mm}$ located above the carina, responsible for a discreet mass effect on the trachea. Axial CT view in parenchymal window showing alveolar filling of the right middle lobe. 
$5 \mathrm{~cm} \times 4 \mathrm{~cm} \times 3 \mathrm{~cm}$, of renitent consistency (Figure 3 ). The cyst had a whitish gelatinous content with a smooth inner and outer surface. Microscopically, there was a cystic wall bordered by a covering of respiratory type ciliated in squamous metaplasia in many areas. This coating was supported by a muscular fibrous connective tissue dissociating glandular islands of the mucous type and supporting numerous vascular elements: compatible with a bronchogenic cyst (Figure 4). The operative consequences were simple; the discharge was authorized on the seventh day. Reviewed at one, two months then at one year and nine months, the child is in perfect health.

\section{Discussion}

Bronchogenic cysts (BC) are among the pulmonary malformations of children

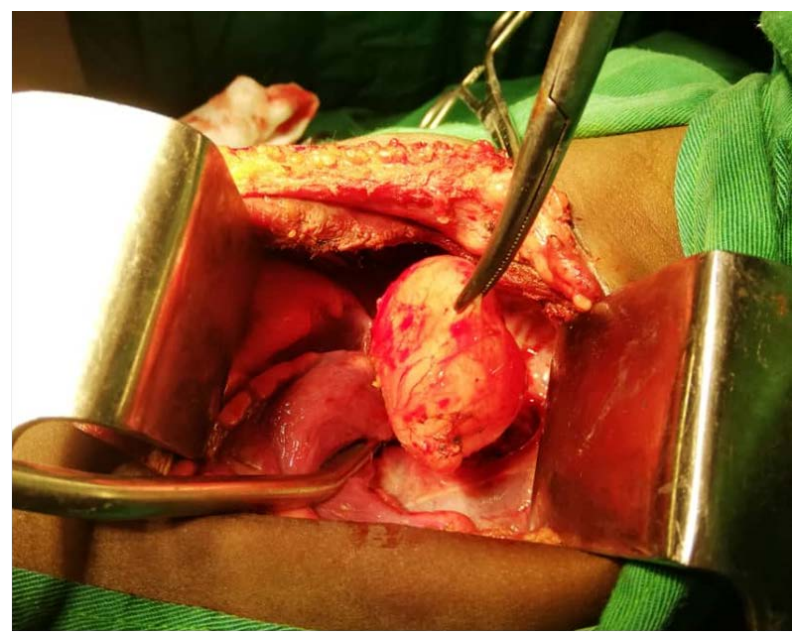

Figure 3. Bronchogenic cyst of $6 \mathrm{~cm} \times 4 \mathrm{~cm}$ in contact with the space of the Baréty compartment, medially and anteriorly with the thoracic wall and the dorsal spine posteriorly.
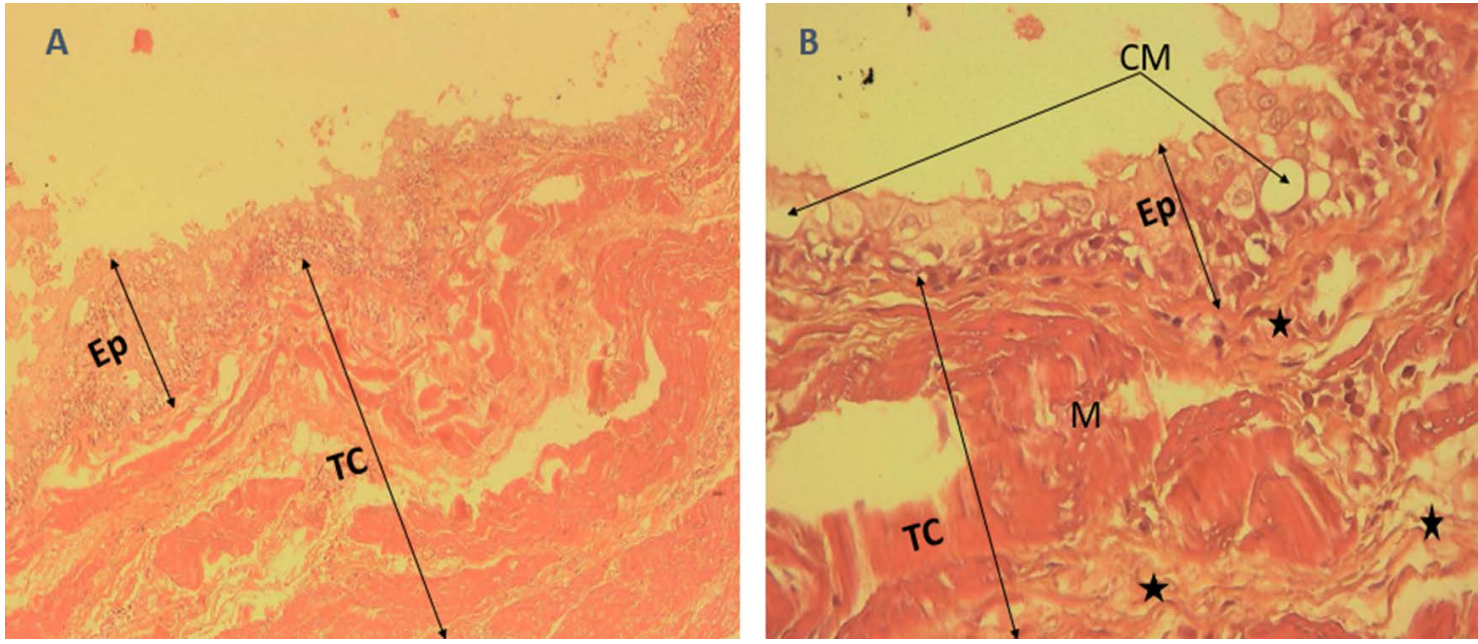

Figure 4. Histological section of the Bronchogenic Cyst. $(\mathrm{A})(\mathrm{HE} \times 10)$ : cystic wall made of a prismatic and pseudo-stratified epithelium (Ep), subtended by connective tissue (TC). (B) (HE $\times 40)$ : Epithelium made up of mucus cells (CM) also called goblet cells, compatible with the epithelium of the bronchi. The subepithelial tissue is made up of muscle components $(\mathrm{M})$ and loose connective tissue $(\star)$ ). 
along with congenital cystic adenomatoid malformations (CCAM), sequestration, giant lobar emphysema and bronchial atresia. These are rare malformations [9] [10].

$\mathrm{BC}$ is an entity of congenital mediastinal cysts, a consequence of an abnormality in the autonomic and delayed development of a cell bud detached from the tracheobronchial tree [9]. They represent $15 \%$ of benign mediastinal tumors [11], $22 \%$ of congenital bronchopulmonary malformations [12] and $10 \%$ to $15 \%$ of pulmonary malformations in children [13]. Their prevalence varies from $1 / 42.000$ to $1 / 68.000$ live births [10].

The location of the $\mathrm{BC}$ depends on the timing of the onset of the gut budding error during embryogenesis. Also, the seat is mediastinal in approximately $65 \%$ when the anomaly occurs between the $20^{\text {th }}$ and $40^{\text {th }}$ day of embryonic life and, in $27 \%$ intraparenchymal or extrathoracic for any anomalies occurring during the third trimester of pregnancy [14] [15] [16]. According to Lemarié and Min, thoracic locations are $70 \%$ pulmonary and 30\% mediastinal [16] [17]. We report here a case of mediastinal localization.

The mechanism of occurrence of a BC is poorly understood. However, an imbalance between the factors which intervene in the control of its development such as FGF, VEGF, TGF and in particular FGF10, liable to induce pulmonary cystic abnormalities have been implicated [17].

The diagnosis of pulmonary malformations is currently possible thanks to advances in antenatal ultrasound which carried out during the fetal period, makes it possible to visualize it in the form of hyperechogenicity and/or cysts [9]. When an antenatal diagnosis has not been possible, clinical symptoms are variable, depending on the size of the cyst which gradually increases with age and/or the effect of mass on adjacent structures [7]. Thus, the cyst may be discovered by unexpectedly, when it is asymptomatic, in particular for those with a peripheral location. When the location is mediastinal, respiratory distress is earlier and the severity varies [18]. This is the case of a bronchogenic cyst discovered in an eight-year-old child after a chronic cough with associated wheezing and periods of bronchial congestion observed since the age of three and several times treated with inhaled corticosteroids in the hypothesis of asthma [8]. The other symptoms likely to guide the diagnosis are: dysphagia in the event of compression of the esophagus, pulmonary infections with repetitions in the event of compression of the airways and in rare cases, cardiac arrhythmias in case of compression of the cavities cardiac [18]. The treatment failure characterized by a progressive worsening of the respiratory distress coupled with the radiological and CT abnormalities in this clinical case as in that of Lefevrea [8] guided the diagnosis. Also, the need for additional examinations in the diagnosis of $\mathrm{BC}$ is well established. Among these examinations is the standard thoracoabdominal X-ray which shows, as found in this clinical case, a mediastinal enlargement with a deviation of the trachea in the event of mediastinal BC. The other tests are CT, better still, chest magnetic resonance imaging. In all cases, the diagnostic certainty is 
pathological [9] [12] [19].

Treatment, mainly surgical, consists of excision of the cyst even when it is asymptomatic. This choice is guided by the always possible occurrence of severe complications [8] [11] [12] including tracheal compression or tracheobronchial obstruction, superinfection promoted by communication between the cyst and the tracheobronchial tree, rupture of the cyst, the occurrence of pneumothorax by hyperinflation of the contralateral lung sometimes accompanied by hemoptysis as well. that the occurrence of cardiac arrhythmias.

Carcinomatous or sarcomatous tumor-like degeneration, although exceptional, has been reported [8] [13] [16] [18] [19]. The evolution of a treated bronchogenic cyst is generally favorable.

\section{Conclusion}

The bronchogenic cyst is a rare pulmonary malformation with late manifestations. In the symptomatic presentations, it can be misleading for a clinician in front of a patient with breathing difficulty and wheezing, which can immediately suggest the diagnosis of bronchopneumopathies, asthma and/or bronchiolitis in infants. Standard conventional radiography, CT scan or chest MRI guide the diagnosis, which is confirmed by histology. Successful removal of the cyst for this clinical case is the only therapy indicated regardless of the clinical presentation. We stress the need to look for pulmonary malformations in children when faced with any wheezing pathology. In all cases, antenatal ultrasound when done helps to avoid diagnostic pitfalls.

\section{Conflicts of Interest}

The authors declare no conflicts of interest regarding the publication of this paper.

\section{References}

[1] Marchac, V. (2007) Différence de diagnostic des infections broncho-pulmonaires virales ou bactériennes chez l'enfant. Arch de pédiatre, 14, 202-206. https://doi.org/10.1016/j.arcped.2006.10.004

[2] Moyen, E., Kambourou, J., Okoko, A.R., Nguelongo, L.B., Bomelefa-Bomel, V., Nkounkou, K.G., Moyen, G. and Nkoua, J.L. (2018) Child Acute Lower Respiratory Tract Infection in Pediatrics Intensive Care Unit at University Hospital of Brazzaville (Congo). Open Journal of Pediatrics, 8, 32-41.

https://doi.org/10.4236/ojped.2018.81005

http://www.scirp.org/journal/ojped

[3] Suen, H.C., Mathisen, D.J., Grillo, H.C., LeBlanc, J., McLoud, T.C., Moncure, A.C., et al. (1993) Surgical Management and Radiological Characteristics of Bronchogenic Cysts. Annals of Thoracic Surgery, 55, 476-481. https://doi.org/10.1016/0003-4975(93)91022-F

[4] Le Pimpec-Barthes, F., Cazes, A., Bagan, P., Badia, A., Vlas, C., Hernigou, A., et al. (2010) Mediastinal Cysts: Clinical Approach and Treatment. Revue de Pneumologie Clinique, 66, 52-62. 
[5] De Baets, F., Van Daele, S., Schelstraete, P., Haerynck, F., Vermassen, F. and Broers, C. (2004) Asphyxiating Tracheal Bronchogenic Cyst. Pediatric Pulmonology, 38, 488-490. https://doi.org/10.1002/ppul.10408

[6] Lahbabi, M., Sadiki, H., Slaoui, B., Jennane, F. and Dehbi, F. (2010) P149. Kyste bronchogénique du nourrisson révélé par une dyspnée sifflante récidivante (À propos de deux cas). Archives de Pédiatrie, 17, 87. https://doi.org/10.1016/S0929-693X(10)70549-2

[7] Hassaine, A., Elbousaadni, Y., Amrani, R., Messaoudi, S., Benhaddou, H., Kamaoui, I. and Skiker, I. (2018) Le kyste bronchogénique médiastinal: A propos d'un cas. Revue de Médecine Périnatale, 10, 194-196.

[8] Lefevrea, C., Marsa, A., Doana, C., Liesseb, A., Bonnevallec, M., Ganga-Zandzou, S., Ythiera, H. and Pouessela, G. (2011) Tableau d'asthme révélant tardivement un kyste bronchogénique. Archives de Pédiatrie, 18, 1336-1338. https://doi.org/10.1016/j.arcped.2011.09.005

[9] Hadchouel, A. and Delacourt, C. (2012) Physiopathologie, diagnostic et prise en charge des malformations pulmonaires de l'enfant. La Lettre du Pneumologue, 15, 126-131.

[10] Schouten Van der Velden, A.P., Severijnen, R.S. and Wobbes, T. (2006) A Bronchogenic Cyst under the Scapula with a Fistula on the Back. Pediatric Surgery International, 22, 857-860. https://doi.org/10.1007/s00383-006-1753-1

[11] Lemarié, E., Le Floch, H., Niang, A., Rivière, F., et al. (2007) Une péricardite atypique. Revue des Maladies Respiratoires, 24, 1147-1150. https://doi.org/10.1016/S0761-8425(07)74267-5

[12] Salles, M., Deschildre, A., Bonnel, C., et al. (2005) Diagnostic et traitement des malformations bronchopulmonaires congénitales: Analyse de 32 observations. Archives de Pédiatrie, 12, 1703-1708. https://doi.org/10.1016/j.arcped.2005.09.013

[13] Takeda, S., Miyoshi, S., Inoue, M., et al. (1999) Clinical Spectrum of Congenital Cystic Disease of the Lung in Children. European Journal of Cardio-Thoracic Surgery, 15, 11-17. https://doi.org/10.1016/S1010-7940(98)00262-0

[14] Radermecker, M.A., Moscato, A., et al. (2002) Les kystes bronchogéniques: Observation clinique et revue de la littérature. Revue médicale de Liège, 57, 45-48.

[15] Laje, P. and Liechty, K.W. (2008) Postnatal Management and Outcome of Prenatally Diagnosed Lung Lesions. Prenatal Diagnosis, 28, 612-618. https://doi.org/10.1002/pd.1966

[16] Lemarié, E., Diot, P., et al. (2005) Tumeurs médiastinales d'origine embryonnaire. EMC-Pneumologie, 2, 105-125. https://doi.org/10.1016/j.emcpn.2005.04.001

[17] Min, H., Danilenko, D.M., Scully, S.A., et al. (1998) Fgf-10 Is Required for Both Limb and Lung Development and Exhibits Striking Functional Similarity to Drosophila Branchless. Genes \& Development, 12, 3156-3161. https://doi.org/10.1101/gad.12.20.3156

[18] Hadchouel-Duvergé, A., Lezmi, G. and de Blic, J. (2012) Malformations pulmonaires congénitales: Histoire naturelle et hypothèses pathogéniques. Revue des Maladies Respiratoires, 29, 601-611. https://doi.org/10.1016/j.rmr.2011.09.049

[19] Nouri-Merchaoui, S., Mahdhaoui, N., Methlouthi, J., Sahnoun, L., Zakhama, R., Nouri, A., et al. (2012) Kyste bronchogénique médiastinal: Cause rare de wheezing chez le nouveau-né. Journal de Pédiatrie et de Puériculture, 25, 102-105. https://doi.org/10.1016/j.jpp.2012.01.001 